\title{
The expression of CD73 on pathological B-cells is associated with shorter overall survival of patients with CLL
}

\author{
M. KICOVA ${ }^{1,2, *}$, Z MICHALOVA $^{1,2}$, M. COMA ${ }^{2}$, J. GABZDILOVA ${ }^{3}$, K. DEDINSKA ${ }^{3}$, T. GUMAN ${ }^{3}$, S. BERNATOVA ${ }^{1,2}$, M. HAJIKOVA ${ }^{1,2}$, M. GIERTLOVA $^{4}$, \\ D. VESELINYOVA ${ }^{4}$, M. SARISSKY $Y^{1,2, *, *}$
}

${ }^{1}$ Central Laboratory of Clinical Cytometry, Department of Pharmacology, Faculty of Medicine, P.J. Safarik University and Medirex, a.s., Kosice, Slovakia; ${ }^{2}$ Department of Pharmacology, Faculty of Medicine, P.J. Safarik University, Kosice, Slovakia; ${ }^{3}$ Department of Hematology and Oncohematology, Louis Pasteur University Hospital and Faculty of Medicine, P.J. Safarik University, Kosice, Slovakia; ${ }^{4}$ Department of Clinical Genetics, Medirex a.s., Kosice, Slovakia

${ }^{*}$ Correspondence: marek.sarissky@upjs.sk

\#Contributed equally to this work.

Received August 26, 2019 / Accepted December 8, 2019

\begin{abstract}
CD73 is a membrane-bound enzyme that catalyzes the extracellular conversion of adenosine monophosphate to adenosine. Adenosine is thought to play a role in promoting tumor growth and survival together with suppressing the host immune responses, which contribute to the multistep process of tumorigenesis. Here, we studied the expression of this antigen in chronic lymphocytic leukemia (CLL). The expression of CD73 was analyzed by multiparametric flow cytometry on normal and pathological B-cells from peripheral blood and bone marrow samples from 71 patients with CLL. Pathological B-cells expressed significantly lower levels of CD73 than normal B-cells $(\mathrm{p}<0.01)$. Patients with splenomegaly showed a higher expression of CD73 on pathological B-cells than patients without splenomegaly $(\mathrm{p}<0.05)$. The expression of CD73 also correlated with beta-2-microglobulin levels $(\mathrm{p}<0.05)$. Clinically, patients with higher levels of CD73 versus those with lower expression presented with shorter overall survival (median OS of 65 vs. 113 months, $p<0.05$ ). Our data indicate that CD73 may play a role in CLL pathophysiology, is correlated with poor clinical and biological prognostic factors and may be of potential value as a prognostic marker and therapeutic target.
\end{abstract}

Key words: CD73, chronic lymphocytic leukemia, B-cells, flow cytometry, immunophenotyping, overall survival

Chronic lymphocytic leukemia (CLL) is the most common type of leukemia in adults characterized by the proliferation and progressive accumulation of mature clonal B-lymphocytes in the peripheral blood, bone marrow, and lymphoid tissues $[1,2]$. The clinical course of the disease is highly variable, some patients require an early treatment because of the disease progression and die from the disease within a few months of the diagnosis, while others display an indolent course that does not affect life expectancy and live for 20 years or more $[2,3]$. Two major clinical staging systems (Binet, Rai) are unable to prospectively discriminate an indolent or aggressive course in individual patients within the low and intermediate-risk categories $[4,5]$. To better differentiate prognostic subsets, several biological parameters [6-11] have been added to the staging systems and many novel potential markers are being investigated. 5 '-nucleotidase (5'-NT), also known as ecto-5'-nucleotidase or CD73 (cluster of differentiation 73), is an enzyme encoded in humans by the NT5E gene located on chromosome 6 (6q14.3). The enzyme consists of a dimer of 2 identical $70 \mathrm{kDa}$ subunits bound by a glycosyl phosphatidyl inositol linkage to the external face of the plasma membrane. CD73 commonly serves to convert AMP to adenosine [12-14]. Several studies have linked CD73 expression to different types of solid tumors (pancreas, lung, ovary, and colon) and several types of hematological malignancies [15-17]. The role of adenosine in tumor biology and apoptosis is controversial. Adenosine is thought to play a role in cell-cell and cell-matrix interactions, promote tumor growth and survival, and suppress the host immune responses, while at the same time it was shown to induce apoptosis through caspase activation, which confers antitumor activity [15-17]. CD73 was also implicated in resistance to chemotherapeutic drugs [18].

In the present study, we analyzed the expression of CD73 on pathological and normal B-cells in patients with CLL by multiparametric flow cytometric immunophenotyping and correlated its expression with selected clinicobiological 
characteristics, cytogenetics, and overall survival of CLL patients.

\section{Patients and methods}

Patients and samples. Peripheral blood $(\mathrm{PB})$ and bone marrow (BM) samples from 71 patients with CLL (for details see Table 1) were collected after obtaining written informed consent. The samples were collected between 2007 and 2010 . All samples were processed within $24 \mathrm{~h}$ of the collection. Diagnostic flow cytometry was performed in fresh samples. The remaining biological material was further processed; lymphocytes were isolated by Ficoll-Urografin density centrifugation, frozen in fetal bovine serum with $10 \%$ DMSO and stored in liquid nitrogen until additional analyses. The diagnosis of CLL was established based on the International Workshop CLL guidelines criteria [19].

Flow cytometric immunophenotyping. In order to establish the immunophenotypic diagnosis of CLL, multiparametric flow cytometric analysis was routinely performed in each patient with a suspicion of chronic B-cell lymphoproliferative disorder using standard 6-color stainings with a panel of antibodies targeted against the following antigens: cluster of differentiation (CD3, CD4, CD5, CD8, CD10, CD11c, CD19, CD20, CD22, CD23, CD27, CD34, CD38, CD43, CD45, CD56, CD79b, CD81, CD103, CD200, FMC7 („Flinders Medical Centre 7“, epitope on CD20), LAIR1 („Leukocyte-Associated Immunoglobulin-like Receptor $\left.1^{\prime \prime}\right)$, mIgM, mIgKappa and mIgLambda. In patients with the established diagnosis of CLL based on the WHO criteria including immunophenotype, the expression of CD73 on the cell surface was analyzed using a phycoerythrin-conjugated mouse monoclonal antibody targeted against human CD73, clone AD2 (Cat\#344044, Biolegend, USA). The cryopreserved CLL samples were used for CD73 analysis. The samples were thawed, washed twice in PBS and processed using a standard stain-lyse-wash technique as described previously [20,21]. After staining, samples were acquired in a FACS Canto flow cytometer (BDBiosciences, USA). The data were analyzed using the Infinicyt v.1.7 software package (Cytognos, Spain). For each sample, the following information was reported separately from normal and pathological B-cells: i) the presence or absence of the analyzed antigen (CD73), ii) the intensity of antigen expression as reflected by the mean fluorescence intensity (MFI) expressed as relative linear arbitrary fluorescence channel units scaled from 0 to $2.5 \times 10^{5}$ of the stained cells after subtracting the MFI obtained for control unstained cells from the same sample. Normal mature B-cells were identified as polyclonal CD5 $5^{\text {neg }}$ $\mathrm{CD} 20^{\text {high }} \mathrm{CD} 19^{\text {pos }}$ cells whereas pathological B-cells were identified as $\mathrm{CD} 5^{\text {pos }} \mathrm{CD} 20^{\text {low }} \mathrm{CD} 19^{\text {pos }}$ cells with monotypic expression of cell surface immunoglobulin light chains.

Interphase fluorescence in situ hybridization (iFISH). Single-cell suspensions of mononuclear cells were obtained from EDTA anticoagulated PB or BM samples by Ficoll-
Urographin (Sigma, Schering, Germany) density centrifugation. The iFISH studies were performed on slides bearing cells fixed in methanol/acetic acid (3:1, v/v) solution and stored at $-20^{\circ} \mathrm{C}$. Analysis of deletions of $6 \mathrm{q}, 11 \mathrm{q}, 13 \mathrm{q}, 17 \mathrm{p}$ and trisomy of chromosome 12 was performed using POSEIDON $^{\mathrm{TM}}$ ON 6q21/SE6 probe (Kreatech, NL), LSI ATM, LSI D13S25, LSI P53 and CEP12 DNA probes (Vysis, USA) as previously described in detail [22]. Denaturation and hybridization steps were performed using a ThermoBRITE hybridizer (Vysis-Abbott, Des Plaines, IL, USA). The slides were counterstained with 4, 6-diamidino-2-phenylindole (DAPI) and the number of hybridization spots and their distribution in the nuclei were evaluated using a BX60 fluorescence microscope (Olympus, Japan). For each slide, the number of hybridization spots per nucleus was counted in at least 200 nuclei; only spots with a similar size, intensity and shape were counted. For all FISH probes used, a 6\% cut off level was established. Frequencies of positive nuclei in individual slides ranged from $12-97 \%$ in del13q; 8-70\% in trisomy 12 ; $10-90 \%$ in del11q; $12-90 \%$ in del17p and $24-80 \%$ in del6q.

Statistical analysis. The data from the fluorescence intensity measurements are expressed as median and mean \pm standard deviation. In order to establish the statistical significance of differences observed between groups, the non-parametric Mann-Whitney U-test was used. For paired samples comparison, the Wilcoxon signed-rank test was employed. For correlation analysis, the Pearson's rho coefficient was calculated. Overall survival (OS), measured from the time of diagnosis, was estimated according to the KaplanMeier method and compared between groups by means of the log-rank test. Statistical significance was considered to be present once $\mathrm{p}$-values were $<0.05$.

\section{Results}

The expression of CD73 was analyzed in pathological and normal B-cells (Figure 1). B-cells represented $25 \pm 14 \%$ of the total cellularity in samples. Normal B-cells were detected in 12 out of 71 patients with CLL and represented $3 \pm 1 \%$ of all B-cells. For both, normal and pathological B-cells, the expression of CD73 did not significantly differ between $\mathrm{PB}$ and BM samples.

However, when compared to normal B-cells, pathological B-cells showed significantly lower CD73 expression ( $817 \pm 1421$ vs. $2900 \pm 1307$, respectively, $p<0.01$; Figures $1 \mathrm{C}$ and $2 \mathrm{~A}$ ). Furthermore, the analysis of eventual relationships between CD73 expression and selected clinicobiological characteristics showed a statistically significant correlation between $\beta-2$ microglobulin levels and the expression of $\operatorname{CD} 73$ ( $\rho=0.362, p<0.05$; Figure $2 C$ ).

Moreover, patients with CLL who had splenomegaly displayed a significantly higher expression of CD73 antigen on pathological B-lymphocytes than patients without splenomegaly ( $1556 \pm 3354$ vs. $400 \pm 1273$; $\mathrm{p}<0.05$; Figure $2 \mathrm{~B}$ ). On the other hand, no correlations were observed between the 

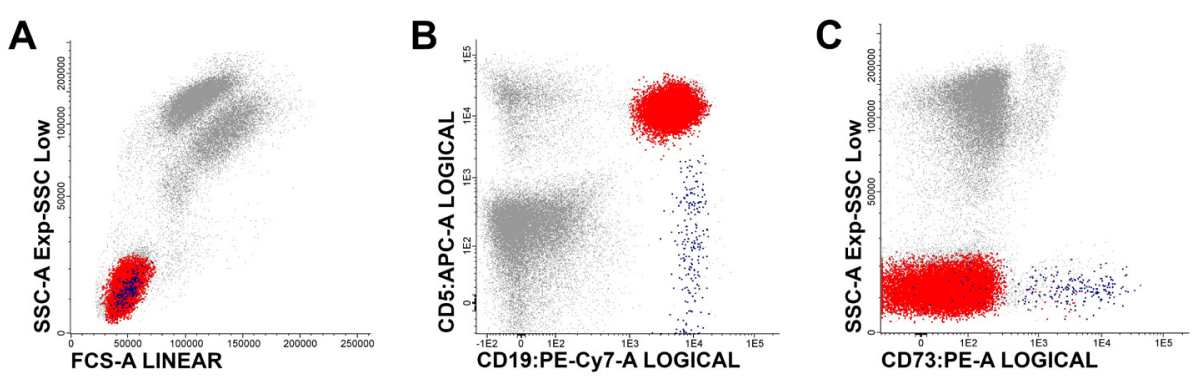

Figure 1. Illustrative bivariate dot plots showing the gating strategy to identify the populations of normal (blue) and pathological (red) B-cells (A, B), and differences in the expression of CD73 observed between normal and pathological B-cells (C), CD: cluster of differentiation; APC: allophycocyanin; PE-Cy7: phycoerythrin-Cy7; FITC: fluorescein isothiocyanate; PE: phycoerythrin; FSC: forward scatter; SSC: side scatter.

A

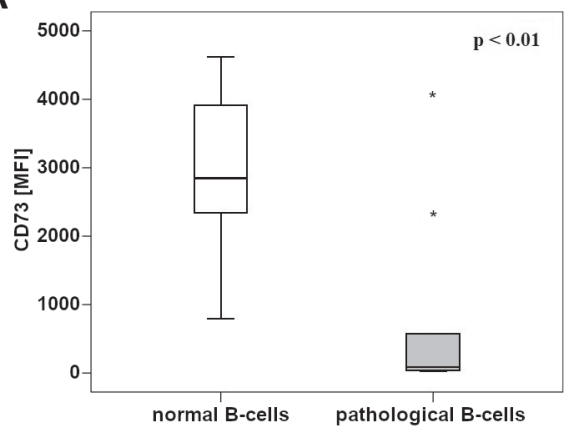

C

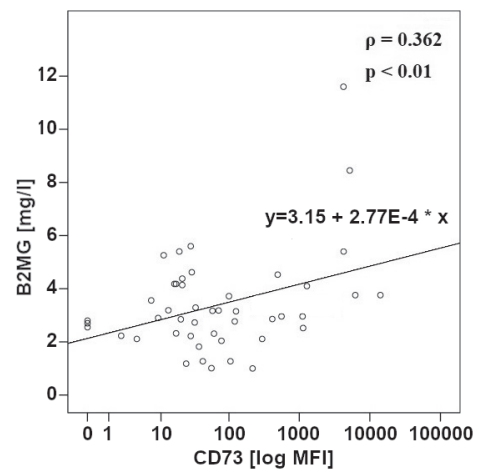

B

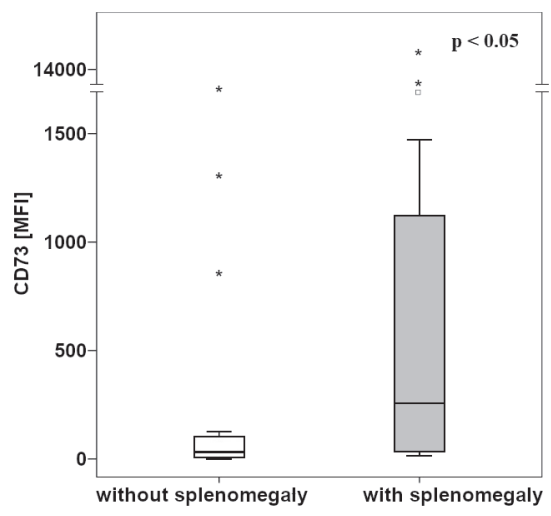

D

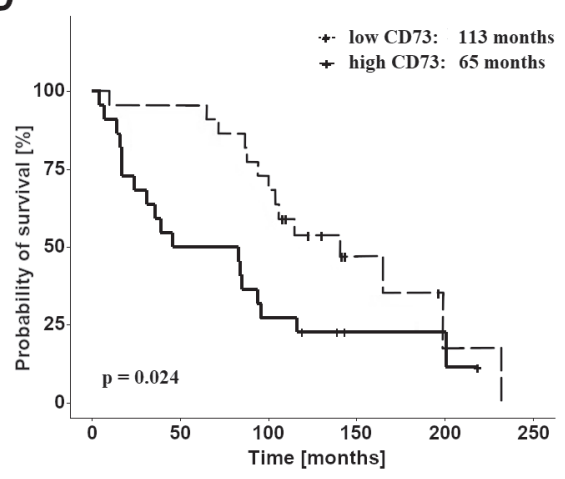

Figure 2. Graphs showing the differences in the expression of CD73 observed between normal and pathological B-cells in patients with chronic lymphocytic leukemia (CLL) (A), between CLL patients with and without splenomegaly (B), the correlation between the expression of CD73 and beta-2microglobulin levels (C), and Kaplan-Meier curves representing the probability of survival in CLL patients with low CD73 expression (<median CD73 MFI, purple) versus patients with high CD73 expression (>median CD73 MFI, blue) (D).

expression of CD73 and the remaining clinicobiological characteristics and cytogenetic findings as determined by iFISH.

From the clinical point of view, we analyzed the expression of CD73 in relation to overall survival (OS) of CLL patients. Only patients whose death was directly related to the primary diagnosis, CLL, were included in the analysis of the relationship between the expression of CD73 and overall survival. Depending on the level of CD73 antigen expression, patients were divided into two groups based on the median MFI value. The median CD73 antigen expression, expressed as MFI, in the whole analyzed CLL group was 61 . The first group consisted of patients in whom the antigen expression value was lower than the median (Figure 2D, dashed line). The second group included patients with expression values higher than the median value (Figure 2D, full line). 
Table 1. Clinicobiological characteristics of patients with CLL ( $n=71)$.

\begin{tabular}{|c|c|c|}
\hline Characteristic & & Value \\
\hline Age (years) & Median (range) & $62(35-87)$ \\
\hline \multirow[t]{2}{*}{ Gender (n,\%) } & Male & $43(61 \%)$ \\
\hline & Female & $28(39 \%)$ \\
\hline \multirow[t]{2}{*}{ Sample type (n,\%) } & $\mathrm{PB}$ & $20(\%)$ \\
\hline & $\mathrm{BM}$ & $51(\%)$ \\
\hline \multirow[t]{2}{*}{ Disease status $(\mathrm{n}, \%)$} & Newly diagnosed/untreated & 35 \\
\hline & Relapsed/treated & 36 \\
\hline ALC, $10^{9} / 1$ & Median (range) & $39(2-144)$ \\
\hline ANC, $10^{9} / 1$ & Median (range) & $52(4-157)$ \\
\hline PLT, $10^{9} / 1$ & Median (range) & $177(13-371)$ \\
\hline $\mathrm{Hb}, \mathrm{g} / \mathrm{l}$ & Median (range) & $129(62-180)$ \\
\hline $\mathrm{B} 2 \mathrm{MG}, \mathrm{mg} / \mathrm{l}$ & Median (range) & $3.4(1-11.6)$ \\
\hline TK, IU/1 & Median (range) & $15(1-46.5)$ \\
\hline \multirow[t]{2}{*}{ Splenomegaly (n,\%) } & with & $20(48 \%)$ \\
\hline & without & $22(52 \%)$ \\
\hline \multirow[t]{2}{*}{ Hepatomegaly (n,\%) } & with & $15(36 \%)$ \\
\hline & without & $27(64 \%)$ \\
\hline \multirow[t]{2}{*}{ Lymphadenopathy (n,\%) } & with & $39(81 \%)$ \\
\hline & without & $9(19 \%)$ \\
\hline \multirow[t]{5}{*}{ Rai stage (n,\%) } & 0 & $3(6 \%)$ \\
\hline & I & $9(19 \%)$ \\
\hline & II & $21(44 \%)$ \\
\hline & III & $4(8 \%)$ \\
\hline & IV & $11(23 \%)$ \\
\hline \multirow[t]{6}{*}{ Cytogenetics (n,\%) } & normal & $17(24 \%)$ \\
\hline & $6 \mathrm{q}$ deletion & $4(6 \%)$ \\
\hline & 11q deletion & $13(18 \%)$ \\
\hline & $13 q$ deletion & $19(27 \%)$ \\
\hline & $17 \mathrm{p}$ deletion & $7(10 \%)$ \\
\hline & Trisomy 12 & $9(13 \%)$ \\
\hline
\end{tabular}

WBC: white blood cell count; ALC: absolute lymphocyte count; ANC: absolute neutrophil count; PLT: platelet count; Hb: hemoglobin; B2MG: beta-2-microglobulin; TK: thymidine kinase. The data on splenomegaly, hepatomegaly, lymphadenopathy and Rai clinical stages were available in $42,42,48$ and 48 patients, respectively. The remaining data were available in all patients.

The relationship between antigen expression level and overall survival was graphically expressed using KaplanMeier curves. The likelihood of overall patient survival was expressed as a dependence of patient survival (in percent) and time from diagnosis (in months). Patients with higher CD73 expression presented significantly shorter survival (Figure 2D, median OS $=65$ months, median CD73 = 809, full line) compared to patients in whom CD73 expression was lower (Figure 2D, median OS $=113$ months, median CD73 = 22 expression, dashed line).

\section{Discussion}

In the present study, we demonstrate by the flow cytometric immunophenotyping that CLL B-cells display a lower expression of CD73 than normal B-cells. Similar results were reported by Pulte et al. [23], who found lower expression of CD73 on both clonal B-cells and T-cells in the majority of CLL patients as well as by Osman et al. [24], who found significantly lower expression of CD73 on both clonal B-lymphocytes and T-lymphocytes in all their patients. Serra et al. [15] tested the CD73 expression in peripheral blood and in lymph nodes of CLL patients and identified $\mathrm{CD}^{+} 3^{+}$and $\mathrm{CD} 73^{-}$CLL patients with approximately a third of the patients harboring $\mathrm{CD} 73^{+} / \mathrm{CD} 19^{+}$populations. Those results were confirmed using RT-PCR, in which CD73 showed undetectable to low levels in approximately half of the patients [15]. The beta-2-microglobulin concentration is associated with the extent of the disease and its more aggressive course [25]. In our CLL patients with stronger CD73 expression, higher levels of beta-2-microglobulin were found, which might indicate a more advanced stage or more aggressive course of the disease. This is consistent with a study in which Serra et al. [15] evaluated the clinical implications of CD73 in chronic lymphocytic leukemia (CLL) and found that high expression of CD73 is associated with more aggressive clinical behavior characterized with larger CLL clone and poor prognostic markers - namely, higher expression of Ki-67, CD38, and ZAP70. In contrast, Pulte et al. [23] suggested that patients with $\mathrm{CD} 73^{+}$CLL have a less aggressive course compared with CD73- CLL, which was associated with more advanced disease. Osman et al. [24] demonstrated significantly lower CD73 expression on T-lymphocytes in patients with Binet stage $\mathrm{C}$ compared with those who had the early-stage disease (A or B) at diagnosis. The presence or absence of lymphadenopathy and organomegaly determines the inclusion of a patient to the appropriate clinical stage according to the Rai's staging system. We found that patients with splenomegaly displayed significantly higher levels of CD73 expression on pathological B-lymphocytes than patients without splenomegaly. In terms of treatment, CD73 is an ecto-5'-nucleotidase enzyme which, together with serum phosphatase, converts fludarabine (administered as 5-nucleotide monophosphate) to a nucleoside. Serra et al. [15] showed that CD73 positive CLL B cells produced adenosine, which was able to inhibit apoptosis of CLL B cells induced by fludarabine. In contrast, Mackey et al. [26] found that higher levels of CD73 mRNA were associated with a trend towards a longer time to disease progression in patients treated with fludarabine. According to our results, high expression of CD73 is associated with shorter overall survival of CLL patients.

To conclude, our data show that the expression of CD73 is lower on pathological than normal B-cells and it is significantly correlated with increased $\beta-2$ microglobulin levels and the presence of splenomegaly, indicating more active and aggressive disease. Most importantly, we found that high expression of CD73 is associated with significantly shorter OS in CLL patients. To the best of our knowledge, this is the first demonstration of the impact of CD73 expression on CLL patients' survival. These results suggest that CD73 
may play a significant role in the pathophysiology of CLL, its expression correlates with disease activity, and it may predict overall survival of CLL patients Furthermore, CD73 might serve as a potential target for the development of novel anticancer drugs.

Acknowledgments: This work was supported by the Grant Agency of the Ministry of Education, Science, Research and Sport of the Slovak Republic (No. VEGA 1/0673/19) and the Internal scientific grant system of Pavol Jozef Šafárik University (No. VVGS-2014217).

\section{References}

[1] GAIDANO G, FOA R, LA-FAVERA R. Molecular pathogenesis of chronic lymphocytic leukemia. J Clin Invest 2012; 122: 3432-3438. https://doi.org/10.1172/JCI64101

[2] ROZMAN C, MONTSERRAT E. Chronic lymphocytic leukemia. N Engl J Med 1995; 333: 1052-1057. https://doi. org/10.1056/NEJM199510193331606

[3] ZENZ T, MERTENS D, KUPPERS R, DOHNER H, STILGENBAUER S. From pathogenesis to treatment of chronic lymphocytic leukaemia. Nat Rev Cancer 2010; 10: 37-50. https://doi.org/10.1038/nrc2764

[4] BINET JL, AUQUIER A, DIGHIERO G, CHASTANG $\mathrm{C}$, PIGUET $\mathrm{H}$ et al. A new prognostic classification of chronic lymphocytic leukemia derived from a multivariate survival analysis. Cancer 1981; 48: 198-206. https:// doi.org/10.1002/1097-0142(19810701)48:1<198::aidcncr2820480131>3.0.co;2-v

[5] RAI KR, SAWITSKY A, CRONKITE EP, CHANANA AD, LEVY RN et al. Clinical staging of chronic lymphocytic leukemia. Blood. 1975; 46(2): 219-234. Blood 2016; 128: 2109. https://doi.org/10.1182/blood-2016-08-737650

[6] MONTSERRAT E, SANCHEZ-BISONO J, VINOLAS $\mathrm{N}$, ROZMAN C. Lymphocyte doubling time in chronic lymphocytic leukaemia: analysis of its prognostic significance. Br J Haematol 1986; 62: 567-575. https://doi. org/10.1111/j.1365-2141.1986.tb02969.x

[7] KEATING MJ, O'BRIEN S, ROBERTSON L, HUH Y, KANTARJIAN H et al. Chronic lymphocytic leukemia - correlation of response and survival. Leuk Lymphoma 1993; 11 Suppl 2: 167-175. https://doi.org/10.3109/10428199309064278

[8] SARFATI M, CHEVRET S, CHASTANG C, BIRON G, STRYCKMANS P et al. Prognostic importance of serum soluble CD23 level in chronic lymphocytic leukemia. Blood 1996; 88: 4259-4264.

[9] DOHNER H, STILGENBAUER S, BENNER A, LEUPOLT E, KRÖBER A et al. Genomic aberrations and survival in chronic lymphocytic leukemia. N Engl J Med 2000; 343: 1910-1916. https://doi.org/10.1056/ NEJM200012283432602

[10] DEL POETA G, MAURILlO L, VENDITTI A, BUCCISANO F, EPICENO AM et al. Clinical significance of CD38 expression in chronic lymphocytic leukemia. Blood 2001; 98: 2633-2639. https://doi.org/10.1182/blood.v98.9.2633
[11] GATTEI V, BULIAN P, DEL PRINCIPE MI, ZUCCHETTO A, MAURILLO L et al. Relevance of CD49d protein expression as overall survival and progressive disease prognosticator in chronic lymphocytic leukemia. Blood 2008; 111: 865-873. https://doi.org/10.1182/blood-2007-05-092486

[12] RESTA R, YAMASHITA Y, THOMPSON LF. Ecto-enzyme and signaling functions of lymphocyte CD73. Immunol Rev 1998; 161: 95-109. https://doi.org/10.1111/j.1600-065x.1998. tb01574.x

[13] COLGAN SP, ELTZSCHIG HK, ECKLE T, THOMPSON LF. Physiological roles for ecto-5'-nucleotidase (CD73). Purinergic Signal 2006; 2: 351-360. https://doi.org/10.1007/ s11302-005-5302-5

[14] MISUMI Y, OGATA S, OHKUBO K, HIROSE S, IKEHARA Y. Primary structure of human placental 5'-nucleotidase and identification of the glycolipid anchor in the mature form. Eur J Biochem 1990; 191: 563-569. https://doi. org/10.1111/j.1432-1033.1990.tb19158.x

[15] SERRA S, HORENSTEIN A, VAISITTI T, BRUSA D, ROSSI $\mathrm{D}$ et al. CD73 generated extracellular adenosine in chronic lymphocytic leukemia creates local conditions counteracting drug induced cell death. Blood 2011; 118: 6141-6152. https://doi.org/10.1182/blood-2011-08-374728

[16] STAGG J, SMYTH MJ. Extracellular adenosine triphosphate and adenosine in cancer. Oncogene 2010; 29: 5346-5358. https://doi.org/10.1038/onc.2010.292

[17] SPYCHALA J. Tumor-promoting functions of adenosine. Pharmacol Ther 2000; 87: 161-173. https://doi.org/10.1016/ s0163-7258(00)00053-x

[18] UJHÁZY P, BERLETH ES, PIETKIEWICZ JM, KITANO H, SKAAR JR, EHRKE MJ, MIHICH E. Evidence for the involvement of ecto-5'-nucleotidase (CD73) in drug resistance. Int J Cancer 1996; 68: 493-500. https://doi. org/10.1002/(SICI)1097-0215(19961115)68:4<493::AIDIJC15>3.0.CO;2-6

[19] HALLEK M, CHESON BD, CATOVSKY D. Guidelines for the diagnosis and treatment of chronic lymphocytic leukemia: a report from International Workshop on Chronic Lymphocytic leukemia updating the National cancer Institute Working Group 1996 guidelines. Blood 2008; 111: 54465456. https://doi.org/10.1182/blood-2007-06-093906

[20] COMA M, TOTHOVA E, GUMAN T, HAJIKOVA M, GIERTLOVA $M$ et al. Altered expression pattern of SLAM family receptors on pathological B cells of patients with chronic lymphocytic leukemia. Leuk Lymphoma 2017; 58: 1726-1729. https://doi.org/10.1080/10428194.2016.1251593

[21] MICHALOVÁ Z, ČOMA M, KIČOVÁ M, GABZDILOVÁ J, DEDINSKÁ K et al. Overexpression of Galectin-3 in Chronic Lymphocytic Leukemia Is Associated With 17p Deletion: A Short Report. Anticancer Res 2019; 39: 2805-2810. https:// doi.org/10.21873/anticanres.13408

[22] GIERTLOVA M, HAJIKOVA M, VASKOVA J, KAFKOVA A, STECOVA $\mathrm{N}$ et al. Cytogenetic abnormalities predict treatment-free interval and response to therapy in previously untreated chronic lymphocytic leukemia patients. Neoplasma 2011; 58: 82-88. https://doi.org/10.4149/neo_2011_01_82 
[23] PULTE D, FURMAN R, BROEKMAN M, DROSOPOULOS JH, BALLARD HS et al. CD39 expression on T lymphocytes correlates with severity of disease inpatients with chronic lymphocytic leukemia. Clin Lymphoma Myeloma Leuk 2011; 11: 367-372. https://doi.org/10.1016/j.clml.2011.06.005

[24] OSMAN N, AHMADY E, MONIRM, ABDELRAZEKE, ELTONSYI. CD73, a potential diagnostic marker in Egyptian patients with chronic lymphocytic leukemia. Menoufia Medical Journal 2017; 30: 128-132. https://doi.org/10.4103/mmj. mmj_50_15
[25] WIERDA W, O'BRIEN S, WANG X. Characteristics associated with important clinical end points in patients with chronic lymphocytic leukemia at initial treatment. J Clin Oncol 2009; 27: 1637-1643. https://doi.org/10.1200/ JCO.2008.18.1701

[26] MACKEY JR, GALMARINI CM, GRAHAM KA. Quantitative analysis of nucleoside transporter and metabolism gene expression in chronic lymphocytic leukemia (CLL): identification of fludarabine-sensitive and -insensitive populations. Blood 2005; 105: 767-774. https://doi.org/10.1182/ blood-2004-03-1046 